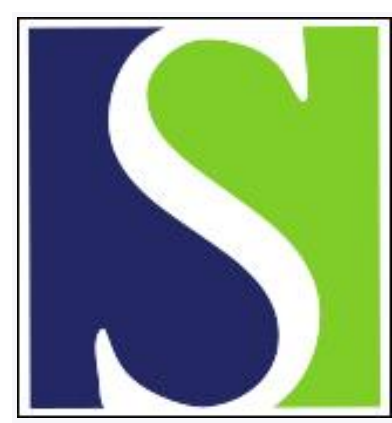

Scand J Work Environ Health 1975;1(2):109-116

https://doi.org/10.5271/sjweh.2858

Issue date: Jun 1975

A health survey of granite workers in Finland: radiographic findings, respiratory function, hearing, electric sensory thresholds of the fingers and subjective symptoms.

by AhIman K, Backman AL, Partanen T

Key terms: dust; electric sensory threshold; finger; Finland; granite work; granite worker; health screening; health survey; hearing; noise; radiographic finding; respiratory function; subjective symptoms; vibration

This article in PubMed: www.ncbi.nlm.nih.gov/pubmed/179134 


\title{
A health survey of granite workers in Finland Radiographic findings, respiratory function, hearing, electric sensory thresholds of the fingers and subjective symptoms
}

\author{
by KAJ AHLMAN, M.D., ${ }^{1}$ ANN-LIS BACKMAN, M.D., ${ }^{2}$ and TIMO PARTANEN, \\ M.Sc. ${ }^{2}$
}

\begin{abstract}
AHLMAN, K., BACKMAN, A-L. and PARTANEN, T. A health survey of granite workers in Finland: Radiographic findings, respiratory function, hearing, electric sensory thresholds of the fingers and subjective symptoms. Scand $j$. work environ. health 1 (1975) 109-116. Results from a health survey of 777 granite workers, exposed to quartz dust, noise and/or machine vibration, and 122 unexposed "controls" are reported. The survey included chest X-rays, pulmonary function tests, a hearing examination, the determination of the electric sensory thresholds of the fingers, and questionnaires on the subjective symptoms of the respiratory system and upper limbs. The exposed workers' radiographic findings (except for a $2.6 \%$ rate of silicosis), respiratory functions, and sensory thresholds did not differ significantly from those of the controls. Granite drillers had a high prevalence of hearing defects. Respiratory symptoms were common among drillers and sandblasters, and subjective symptoms of the upper limbs due to vibration occurred among the granite dressing workers who used pneumatic hammers. Both primary and secondary measures of prevention are strongly recommended for the granite industry, primarily for quartz dust exposure and its health effects.
\end{abstract}

Key words: granite work, dust, noise, vibration, health screening.

Exposure to quartz-containing dust is a well-known health hazard in the granite industry, and most of the previous studies concerning the health hazards of granite work deal with the effects of granite and quartz dust, particularly silicosis (e.g., 1, $2,4,5,6)$. However, recent changes in working methods and the introduction of new tools have created additional health hazards, of which machine noise and vibration are considered the most serious.

This report is the first in a series of reports concerning Finnish granite workers' exposure to dust, noise, and vibration and their health status, morbidity, dis-

1 Outokumpu Oy, Helsinki, Finland.

2 Institute of Occupational Health, Helsinki, Finland.

Reprint requests to: Dr. Kaj Ahlman, Töölönkatu 4, 00100 Helsinki 10, Finland. ability, and subjective opinions of exposure and health-related matters. Specifically, results are reported here of a health screening offered to granite workers; ${ }^{3}$ the screening was directed toward postulated effects of dust, noise, and vibration, namely, effects on the respiratory organs and hearing, as well as circulatory, neurological, and other disturbances in the upper limbs.

\section{SUBJECTS AND THEIR CLASSIFICATION}

A mobile clinic visited 71 plants in the granite industry between 1970 and 1972 . The plants were involved in quarrying,

3 Tunnel and road construction workers were excluded. 
dressing, cutting, crushing, grinding, smoothing, polishing, loading, and transporting rock, granite products and byproducts of the stone processing. These 71 plants were selected from the total of approximately 270 granite plants in the country so that their geographical distribution would correspond to that of the total. The total number of workers in the Finnish granite industry (tunnel and road construction workers excluded) amounts to approximately 2,100 workers. The number of workers estimated to have worked in the selected 71 plants at the time of the screening was 1,300 , out of which 1,037 subjects attended the screening. The participation rate was thus about $80 \%$.

The subjects were classified into 11 groups according to their questionnaire responses as to the kind of granite work they had done and for how long. The groups were the following:

Refining: 96 men who did mixed refining work, mainly crude shaping, cutting and dressing. Owing to the mixed nature of the work, the exposures characterizing this group were various degrees of dust, noise, and vibration. Minimum exposure: 1 year.

Loading: 53 men whose predominant work in the granite industry was the dustexposed loading of granite blocks or sand for transportation. Minimum exposure: 1 year.

Crushing and grinding: 76 men who orushed, grinded, sand sifted, or did related works involved in the processing of granite waste. Dust and noise were the predominant exposures. Minimum exposure: 1 year.

Quarrying: 91 men who worked in the quarries but had an otherwise poorly specified occupational history.

Drilling: 98 men whose predominant work was drilling and shotfiring granite rock. Minimum exposure: 1 year.

Transportation: 135 truck drivers who transported sand and cther forms of gran-

4 The reason why the participation rate is not exactly known is that the research team did not have the exact number of workers in the selected plants. In addition, the employers handled the scheduling of the screening in their respective enterprises. They had been asked to include every employee, but it is not known if they did. ite, with obvious exposure to granite dust. Transport drivers of quarries were not included. Minimum exposure: 1 year.

Dressing: 59 men who used pneumatic or hand-operated hammers in the rough smoothing of the granite block surfaces. Exposure involved dust, noise, vibration, and flying pieces of granite. Minimum exposure: 1 year.

Sawing: 39 men who split large blocks of granite with mechanical saws. Water spraying was used in this procedure to protect the saw operator from significant exposure to dust. Noise was the predominant exposure. Minimum exposure: 1 year.

Smoothing and polishing: 55 men who mechanically rubbed the granite surfaces with an abrasive disk. Water spraying was used except for the final polishing where tin ash could be used with no water. Dust exposure was slight; noise was probably the most notable exposure. Minimum exposure: 1 year.

Sandblasting: 75 men who leveled or engraved granite surfaces by pneumatically blasting sand on the surface or parts thereof. The level of exposure depended upon how the work was done. In open blasting the operator worked in a shed, and, if not properly protected with personal pnotection equipment, he was directly exposed to granite dust and noise. A less dangerous mode of sandblasting was done by direating the sandblast from outside a shed, which was equipped with ventilation for dust removal. Minimum exposure: 3 months.

"Control" group: 122 men employed in the granite industry at the time of the screening whose exposure to dust, noise, and vibration had been, according to their own report, shorter than 3 months. Most of their working history consisted of work other than office work.

A total of 899 persons were included in the 11 groups. The remaining 138 were excluded for one of the following reasons: (a) insufficiently reported working history, (b) office work, (c) "confounding" exposure (e.g., mining), (d) sex (women were excluded because of their small number), (e) age (those under 15 and over 64 years of age were excluded for the same reason as the women).

The age distributions of the 11 groups can be found in table 1 . 
Table 1. Age structure of the 11 groups of granite workers.

\begin{tabular}{|c|c|c|}
\hline Group & $\underset{(\mathrm{yr})}{\text { Median }}$ & $\begin{array}{c}\text { Proportion } \\
\text { of subjects } \\
\text { in age group } \\
45-64 \text { yr } \\
(\%)\end{array}$ \\
\hline Refining & 47.2 & 59 \\
\hline Loading & 28.7 & 10 \\
\hline Crushing and grinding & 43.0 & 47 \\
\hline Quarrying & 38.6 & 28 \\
\hline Drilling & 38.0 & 32 \\
\hline Transportation & 30.9 & 13 \\
\hline Dressing & 49.8 & 68 \\
\hline Sawing & 37.5 & 33 \\
\hline Smoothing and polishing & 40.0 & 38 \\
\hline Sandblasting & 30.7 & 22 \\
\hline Control group & 29.0 & 19 \\
\hline All & 36.5 & 32 \\
\hline
\end{tabular}

\section{PROCEDURE AND METHODS}

\section{Screening procedure}

The granite workers were requested to fill out two questionnaires, one on respiratory symptoms and smoking habits (8) and one on different symptoms of the upper limbs (9). They were to bring the completed questionnaires to the mobile clinic where a nurse checked all the information and interviewed those men who used vibrating tools in their work. The screening procedure then followed: height and weight were recorded, two chest radiographs (antero-posterior and lateral) taken, respiratory function tests (forced vital capacity and 1-second forced expiratory volume) made, ${ }^{5}$ and hearing checked. Also the electric sensory thresholds of the fingers of the 336 men who used vibrating tools were determined.

\section{Health indicators}

Two types of health indicators were considered when the results were evaluated. One type is categorized by the subjective symptoms obtained from the two ques-

5 Each subject made three expirations. The vital capacity values were determined as the percentage of the age-, sex- and heightstandardized normal values (3). The l-second expiratory volumes were computed as the percentage of the vital capacities. tionnaires; the other, by the objective results of the screening tests. The following list includes the health indicators from the screening tests: (a) radiographic findings: normal, suspected tuberculosis of the lung, abnormalities of the pleura, silicosis, fibrosis of the lung, and tumors and infiltrates of the lung; (b) audiometric findings: hearing normal, hearing insignificantly or slightly reduced, hearing significantly reduced, hearing injured by occupation, as judged by the otologist; (c) respiratory function: forced vital capacity percentage of normal ( $\mathrm{VC}, \% \mathrm{~N})(3)$, 1 -second forced expiratory volume percentage of vital capacity (FEV, \% \%); d) neurological examination: the electric sensory threshold of the fingers (normal, borderline, mildily deviant, or strongly deviant).

\section{Statistical methods}

The comparison of the health indicators between the ten exposed groups and the control group was done in two ways according to the type of indicator. In the case of a yes-no type of indicator, agestandardized prevalences were calculated for the exposed groups by using the age distribution of the controls as the standard. The standardization was made through the 15- to 64-year range in 10-year age groups, except for the stone dressers whose youngest member was older than 24; in this group the prevalences were calculated and standardized in the narrower range of 25 to 64 years. The difference of each standardized prevalence and the corresponding prevalence in the controls was tested for significance with Mantel and Haenszel's (7) method of combining information from several $2 \times 2$ frequency tables. Estimates of "risk ratios" were calculated by dividing the standardized prevalences by the prevalence in the control group.

When dealing with health indicators of a continuous nature (respiratory functions), the effects of the different age struatures of the groups were eliminated by calculating the regression lines of each respiratory function variable with respect to age and then comparing the slopes of these lines to those of the controls. The slopes showed the rate of decrease in the respiratory functions with increasing age. 
Table 2. Age-standardized prevalences (\%) of subjective respiratory symptoms and corresponding risk ratios. The latter are shown only if greater than unity at $\mathbf{p}<0.05$.

\begin{tabular}{|c|c|c|c|c|c|c|c|c|c|c|c|c|}
\hline $\begin{array}{l}\text { Respiratory } \\
\text { symptom }\end{array}$ & 苞 & 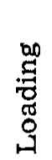 & 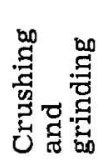 & 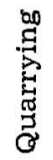 & 崫 & 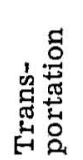 & 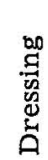 & 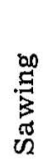 & 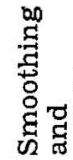 & 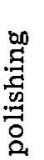 & 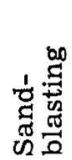 & 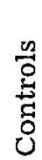 \\
\hline
\end{tabular}

\section{Cough in the morning}

$\begin{array}{lccccccccccc}\text { Stand. prev. } & 38 & 29 & 33 & 22 & 40 & 25 & 31 & 14 & 18 & 17 & 20 \\ \text { Risk ratio } & 1.9 & & & & 2.0 & & \end{array}$

Cough during the day or night

$\begin{array}{llllllllllll}\text { Stand. prev. } & 28 & 15 & 13 & 15 & 24 & 18 & 14 & 13 & 7 & 18 & 20\end{array}$

Cough at least 3 months a year

$\begin{array}{llllllllllll}\text { Stand. prev. } & 23 & 18 & 11 & 14 & 21 & 15 & 28 & 14 & 6 & 20 & 13\end{array}$

Risk ratio 1.4

Phlegm in the morning

$\begin{array}{lllllcllllll}\begin{array}{l}\text { Stand. prev. } \\ \text { Risk ratio }\end{array} & 44 & 41 & 43 & 31 & 45 & 35 & 52 & 41 & 33 & 52 & 29 \\ \end{array}$

Phlegm during the day or night

$\begin{array}{lccccccccccc}\text { Stand. prev. } & 40 & 24 & 21 & 17 & 37 & 26 & 45 & 21 & 15 & 39 & 18 \\ \text { Risk ratio } & 2.2 & & & & 2.0 & & 2.1 & & & 2.1 & \end{array}$

Phlegm at least 3 months a year

$\begin{array}{llllllllllll}\text { Stand. prev. } & 32 & 24 & 18 & 15 & 35 & 18 & 35 & 17 & 12 & 30 & 12\end{array}$

$\begin{array}{llrrrr}\text { Risk ratio } & 2.6 & 2.8 & 2.2 & 17 & 12\end{array}$

Weather affects the chest

$\begin{array}{llllllllllll}\text { Stand. prev. } & 16 & 10 & 5 & 11 & 17 & 8 & 15 & 1 & 7 & 11 & 8\end{array}$

$\begin{array}{llrrr}\text { Risk ratio } & 10 & 11 & 2.2\end{array}$

Runny nose often

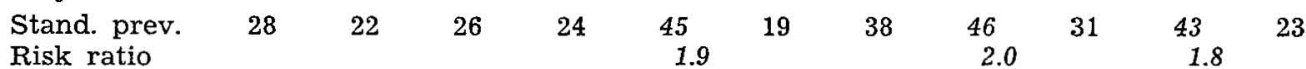

Runny nose at least 3 months a year

$\begin{array}{llllllllllll}\text { Stand. prev. } & 25 & 13 & 16 & 21 & 28 & 11 & 30 & 30 & 25 & 35 & 18\end{array}$

Risk ratio

$\begin{array}{llllllllllll}\text { Stand. prev. } & 38 & 26 & 25 & 31 & 32 & 18 & 38 & 11 & 16 & 32 & 14\end{array}$

$\begin{array}{llllll}\text { Risk ratio } & 2.6 & 2.2 & 4.6 & 2.3\end{array}$

\section{RESULTS}

\section{Subjective respiratory symptoms}

The prevalences of different respiratory symptoms were highest in the drilling, sandblasting, and refining groups (table 2). The drillers complained of coughs, phlegm production, runny noses, chest or throat inflammations, and the effects of weather on the chest; the age-standardized prevalences of these symptoms were 1.5 to 2.8 times those of the controls. The sandblasters complained of phlegm production, runny noses, and inflammations of throat and chest ("significant" risk ratios 1.7-2.4). High prevalences of cough, phlegm production, and inflammations were also noted in the refining group, and those for production of phlegm and inflammations in the dressing group. The quarrying group complained of inflammations, the truck drivers (transportation group) of coughs, and the granite saw operatiors of runny noses.

Subjective and objective symptoms and signs of the upper limbs

The prevalences of subjective symptoms in the upper limbs (table 3) were notably high in the dressing group, a large proportion of which had been using a pneumatic 
Table 3. Age-standardized prevalences ( $\%$ ) of subjective symptoms in the upper limbs and corresponding risk ratios. The latter are shown only if greater than unity at $p<0.05$.

\begin{tabular}{|c|c|c|c|c|c|c|c|c|c|c|c|}
\hline $\begin{array}{l}\text { Subjective } \\
\text { symptoms }\end{array}$ & 离 & ㅁo & 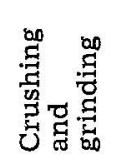 & 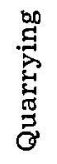 & 品 & 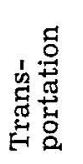 & 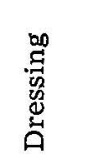 & 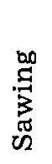 & 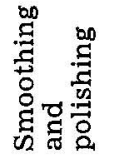 & 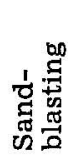 & 菅 \\
\hline \multicolumn{12}{|c|}{ Numb fingers sometimes or often } \\
\hline $\begin{array}{l}\text { Stand. prev. } \\
\text { Risk ratio }\end{array}$ & 30 & 31 & 22 & 30 & $\begin{array}{l}42 \\
1.9\end{array}$ & 18 & $\begin{array}{l}70 \\
1.9\end{array}$ & 19 & 21 & 26 & 22 \\
\hline \multicolumn{12}{|c|}{ Whitening or circulatory disturbances of fingers sometimes or often } \\
\hline $\begin{array}{l}\text { Stand. prev. } \\
\text { Risk ratio }\end{array}$ & $\begin{array}{l}33 \\
1.7\end{array}$ & 16 & 14 & 21 & 26 & 11 & $\begin{array}{l}66 \\
3.2\end{array}$ & 11 & 15 & 24 & 19 \\
\hline \multicolumn{12}{|c|}{ Pains in either wrist sometimes or often } \\
\hline $\begin{array}{l}\text { Stand. prev. } \\
\text { Risk ratio }\end{array}$ & 31 & 12 & 11 & 17 & 31 & 12 & $\begin{array}{l}48 \\
2.2\end{array}$ & 11 & 11 & 14 & 16 \\
\hline \multicolumn{12}{|c|}{ Pains in either elbow or shoulder sometimes or often } \\
\hline $\begin{array}{l}\text { Stand. prev. } \\
\text { Risk ratio }\end{array}$ & 35 & 18 & 13 & 19 & 36 & 23 & $\begin{array}{c}64 \\
1.8\end{array}$ & 23 & 23 & 16 & 21 \\
\hline
\end{tabular}

hammer for a considerable time. Drillers also complained of numb fingers in a significantly higher frequency than the controls, while refiners reported whitening or circulatory disturbances in their fingers.

Of the 336 subjects who reported having been exr:osed to vibration, 322 estimated the time period from the onset of exposure to the first appearance of their symptoms. The following median induction periods were obtained a) 5.4 years for refining, b) 4.2 years for drilling, and c) 7.4 years for dressing. In other words, symptoms developed the fastest in drillers and the slowest in dressers.

The same 322 workers also reported their opinions of what condition or conditions had caused their symptoms. The causing conditions, ranked according to the percentage of those who reported them as causes, were the following: (a) vibration itself $(76 \%)$, (b) frost $(37 \%)$, (c) working posture $(18 \%)$, (d) long, uninterrupted working periods $(6 \%)$, and (e) lack of varying work phases $(5 \%)$.

The electric sensory threshold in the fingers was classified as a) normal, b) borderline, c) mildly deviant, or d) strongly deviant. The two latter categories were then combined, and the prevalences of deviant findings were calculated and standardized for age in each occupational group. The standardized prevalence rates in the different groups of exposed workers ranged from $0 \%$ (crushing and grinding) to $25 \%$ (dressing); none differed significantly, however, from the prevalence in the control group $(12 \%)$.

\section{Radiographic findings}

The age-standardized prevalences of fibrosis of the lung in the eleven groups were based on $100 \times 100$ antero-posterior and lateral chest radiographs. The highest prevalences were noted among the dressing workers $(6.7 \%)$, drillers $(5.6 \%)$, and sandblasters $(5.6 \%)$. According to the unpublished results of Ahlman et al. dressing, drilling, and sandblasting were also works in which high concentrations of quartz dust were measured in the air samples taken in the respiration region of the workers. The prevalences of fibrosis of the lung did not however differ significantly from that of the controls $(0.8 \%)$. Noticeably lower rates were obtained for refining $(2.6 \%)$, loading $(1.2 \%)$, crushing and grinding $(2.8 \%$ ), quarrying $(0.9 \%)$, sawing (1.3), smoothing and polishing $(2.3 \%)$.

Silicosis was provisionally diagnosed in 20 granite workers from the chest radiographs. Three cases were formerly known, four were new and verified by full-sized chest radiographs after screening, eight turned out to be false positives, and five 


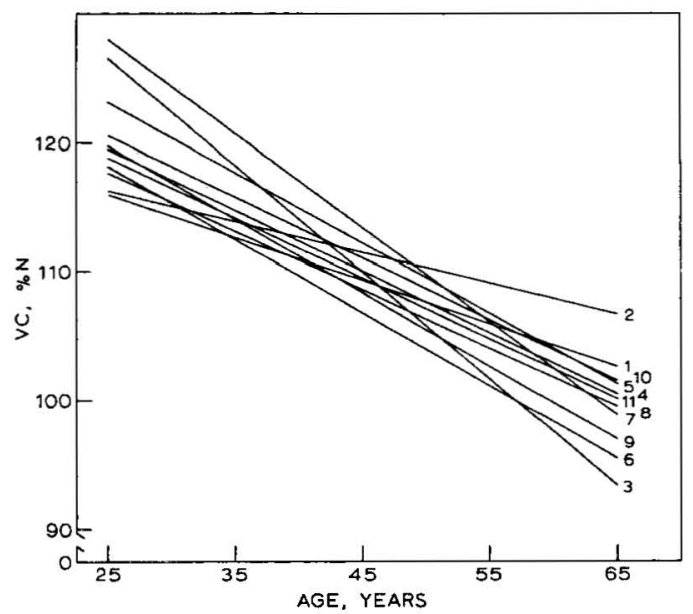

Fig. 1. Age-standardized vital capacity $(\%)$ as a function of the age of the granite workers. (1 = refining, 2 = loading, $3=$ crushing and grinding, $4=$ quarrying, $5=$ drilling, $\quad 6=$ transportation, $7=$ dressing, $8=$ sawing, $9=$ smoothing and polishing, $10=$ sandblasting, and $11=$ controls)

did not comply with the recommendation that their results be verified. The shortest induction period (time from the onset of exposure to quartz dust to diagnosis) in the seven formerly known or freshly diagnosed cases of silicosis was 18 years, and the longest 38 years.

Radiographic signs of abnormadities in the pleura (without silicosis) were seen in $9 \%$ of the exposed ( $12 \%$ in the controls); suspected tuberculosis of the lung, in $0.3 \%$ (none in the controls); and tumors or infiltrates of the lung, in $0.4 \%$ (none in the controls).

\section{Respiratory function}

Vital capacity ( $\%$ of age-, sex- and heightstandardized normal values) and forced expiratory volume $(1.0 \mathrm{~s} ; \%$ of $\mathrm{VC})$ were regressed against age for each group of workers (fig. 1 and 2). The slopes of the regression lines, indicating the rate of decrease with age, of the VC and $\mathrm{FEV}_{1.0}$ of the exposed groups did not differ significantly from the slopes of $\mathrm{VC} /$ age and $\mathrm{FEV}_{1.0} /$ age of the controls. Attention should be drawn to the fact that the vital capacity, although standardized for age, still showed a decreasing tendency with increasing age in this analysis, even for the controls.

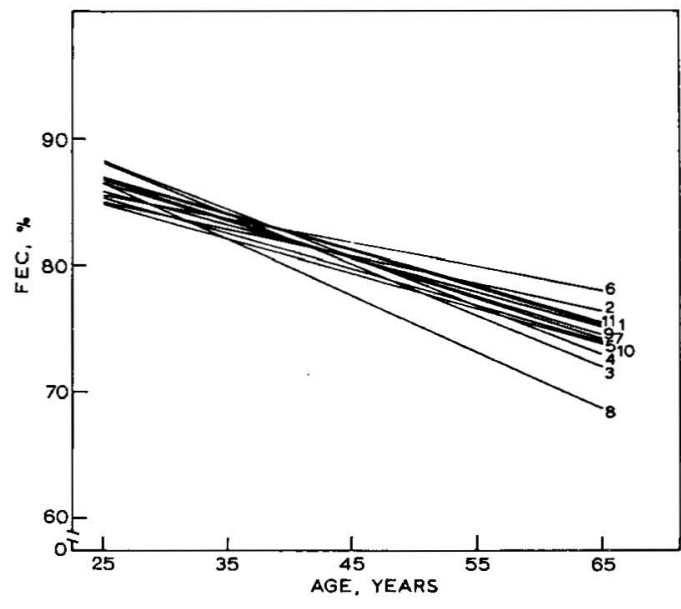

Fig. 2. Forced expiratory volume in $1 \mathrm{~s}(\% \%$ of vital capacity) as a function of the age of the granite workers. $(1=$ refining, $2=$ loading, $3=$ crushing and grinding, $4=$ quarrying, $5=$ drilling, $6=$ transportation, $7=$ dressing, $8=$ sawing, $9=$ smoothing and polishing, $10=$ sandblasting, and $11=$ controls)

\section{Hearing defects}

General deviations from normal hearing (either insignificant, slight or significant) were noted in $50 \%$ of the controls (table 4). The corresponding prevalences in the exposed groups varied between 39 and $61 \%$. The latter figure was observed in the drillers, and it differed from the reference value (controls) at $\mathrm{p}<0.05$.

The prevalences of hearing injury, caused by occupation, ranged from 3 to $58 \%$, while the figure for controls was $44 \%$. No exposed group showed a significantly higher prevalence than that of the controls.

\section{DISCUSSION}

The picture of granite workers' health which emerges from the results is incomplete, if interpreted in terms of the effects of exposure. There are two mutually interlocking reasons: a) the crosssectional nature of screening made it impossible to estimate incidence rates and other risk measures derived from them; instead prevalence rates, specific for the time of screening, were calculated; b) only workers employed in the granite industry at the time of the screening were included; 
Table 4. Age-standardized prevalences of hearing abnormalities and the corresponding risk ratios. The latter are shown only if greater than unity at $\mathrm{p}<0.05$.

\begin{tabular}{|c|c|c|c|c|c|c|c|c|c|c|c|}
\hline $\begin{array}{l}\text { Hearing } \\
\text { abnormalities }\end{array}$ & 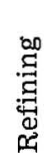 & $\stackrel{\infty}{\infty}$ & 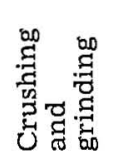 & 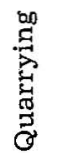 & 照 & 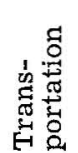 & $\begin{array}{l}.00 \\
\text { : } \\
0 \\
0 \\
0\end{array}$ & 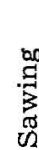 & 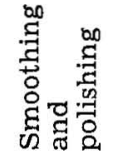 & 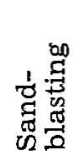 & 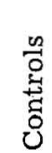 \\
\hline
\end{tabular}

General deviations in hearing from normal (unsignificant, slight or significant)

\begin{tabular}{lccccccccccc}
$\begin{array}{l}\text { Stand. prev. } \\
\text { Risk ratio }\end{array}$ & 61 & 60 & 53 & 46 & 61 & 44 & 98 & 39 & 52 & 59 & 50 \\
Hearing injury caused by occupation & & 1.2 & & & & & & \\
$\begin{array}{l}\text { Stand. prev. } \\
\text { Number of }\end{array}$ & 33 & 13 & 34 & 44 & 47 & 3 & 47 & 58 & 53 & 48 & 44 \\
subjects & 69 & 23 & 44 & 61 & 75 & 53 & 51 & 22 & 33 & 41 & 50 \\
\hline
\end{tabular}

this resulted in the exclusion of those exposed who had left the industry for various reasons, some of which have been related to health (death, incapacity for work, shift for health reasons to work without exposures typical to the granite industry). A longitudinal, retrospective cohort study concerning mortality and incidence of disability of the granite workers will be reported in a later article of this series.

The outcome of a health screening also depends on the sensitivity and the specificity of the screening tests applied. In the present study subjective symptoms proved to be more sensitive indicators of slight health disturbances than the clinical tests. Furthermore, in the unpublished results of Ahlman et al. dust, noise, and vibration measurements, taken in different work places, confirmed the questionnaire results.

According to the results the present working methods of the granite industry seem to increase the risk of respiratory illness, hearing loss, and vibration disease. The highest health risks were noted in the groups occupied with drilling, dressing, refining, and sandblasting.

Respiratory symptoms were frequent in the drilling, sandblasting, and refining groups. Some of the symptoms (for instance symptoms of common cold and chest and throat inflammations) may originate fram weather conditions, since many work phases take place out-of-doors. Another contributing factor may well have been the person-to-person spread of infection.
The radiographic findings showed the highest prevalences of fibrosis of the lung among the dressing workers, drillers, and sandblasters. According to the unpublished results of Ahlman et al. dressing, drilling, and sandblasting were also works in which high concentrations of quartz dust were measured in the air samples taken in the respiration region of the workers. The prevalences of fibrosis of the lung did not however differ significantly from that of the controls.

Silicosis was verified in seven cases. The verified cases derived from the dressing, drilling, refining, or quarrying group.

Dressing workers, drillers, and refiners were the most likely to be affected by vibration. The median exposure time before the vibration symptoms set in ranged from 4 to 7 years. Symptoms developed the fastest in drillers and the slowest in dressers. In measuring the electric sensory threshold in the fingers, we found the highest prevalence of deviant findings in the dressing group; the difference did not, however, reach the adopted significance level.

In evaluating the results, one must bear in mind that many of the subjects in the control group had been exposed to the same health hazards as the other groups, although their exposure time was very short. The eventual effects of exposure must therefore be considered, especially in respect to the audiometric findings. According to the audiometric findings, half of the control group showed deviations from normal. The prevalence of noise-induced hearing loss was as high as 
$44 \%$ among the controls. This figure indicates that there was a possibility that the hearing of the control group was affected in spite of their short exposure time.

In the Finnish granite industry little attention has been paid to preventive measures, and the working conditions are, for the most part, unsatisfactory. It is obvious that primary prevention, including dust control and noise and vibration abatement, must be begun on the technical level. Dust exposure should be monitored regularly with air sampling and analysis in the whole granite industry. More attention should also be directed toward the workers themselves. In the preemployment health examination, as well as in the annual checkups, special attention should be paid to respiratory, circulatory, and auditory conditions. Subjective symptoms would especially help to reveal slight respiratory and circulatory disturbances. Health education ought to be implemented also to promate the importance of warm clothing and the aggravating effect of smoking when one works with vibrating tools. In addition the usefulness of personal protection devices should be emphasized. Shortening the working periods should be seriously considered for persons using vibrating tools.

\section{ACKNOWLEDGMENTS}

This study has been financially supported by the Social Insurance Institution of Finland.

Received for publication: 1975-01-02
The electric sensory threshold measurements were supervised and interpreted by Anna Maria Seppäläinen, M.D. The audiograms were classified by Eero $\mathrm{Va}$ heri, M.D. The radiographs were read and classified by Matti Wiikeri, M.D.

\section{REFERENCES}

1. AHLMAN, K. Silicosis in Finland. Workenviron.-health 4 (1968): suppl. 1, 27-29.

2. AHLMARK, A., BRUCE, T. and NYSTROM, A. Silikosis inom svensk stenindustri. Opusc. med. (Stockh.) (1965): 3, 3-7.

3. BALDWIN, E. F., COURNAND, A. and RICHARDS, D. W., JR. Pulmonary insufficiency: I. Physiological classification, clinical methods of analysis, standard values in normal subjects. Medicine (Baltimore) 27 (1948) 243-278.

4. GRUNDORFER, W. and RABER, A. Progressive silicosis in granite workers. $\mathrm{Br} . j$. ind. med. 27 (1970) 110-120.

5. HALE, L. W. and SHEERS, G. Silicosis in West Country granite workers. Br. j. ind. med. 20 (1963) 218-225.

6. IRMSCHER, G. and VORPAHL, K. Silikosen und Silikotuberkulosen nach kurzen Expositionszeiten. Monatsschr. Lungenkr. Tuberkulosebekämpf. 15 (1972) 97-124.

7. MANTEL, N. and HAENSZEL, W. Statistical aspects of the analysis of data from retrospective studies of disease. J. natl. cancer inst. 22 (1959) 719-748.

8. MEDICAL RESEARCH COUNCIL'S COMMITTEE ON THE AETIOLOGY OF CHRONIC BRONCHITIS. Standardized questionnaires on respiratory symptoms. Br. med. j. 2 (1960) 1665.

9. SEPPÄLÄINEN, A. M. Peripheral neuropathy in forest workers: A field study. Work-environ.-health 9 (1972) 106-111. 